\title{
Optimising the age, number of tests, and test interval for cervical screening in Canada
}

\author{
YU SHUN-ZHANG, A. B. MILLER, AND G. J. SHERMAN \\ From the NCIC Epidemiology Unit, University of Toronto
}

SUMmARY Different approaches to screening for cancer of the cervix by cervical cytology have been evaluated using a computer simulation model developed by Knox and data on the natural history of carcinoma-in-situ (or worse) from a cohort study of women screened in British Columbia, 1949-69. The natural history input parameters and the output parameters without screening were modified to reflect the earlier onset of carcinoma-in-situ in younger cohorts now being experienced in British Columbia, resulting in simulated mortality from carcinoma of the cervix approximately 50\% greater than that experienced in Canada in 1955.

The simulations showed that the sensitivity of the test and the proportion of women in the population who accept invitations to attend for screening materially influence the extent to which programmes reduce mortality. Missed screens also have an important impact.

With a $75 \%$ test sensitivity, and an $80 \%$ population acceptance, a programme designed to reduce mortality by $90 \%$ would commence at age 25 , involve triennial screens to age 52 , or triennial screens to age 40 and quinquennial screens to age 60 , a total of 10 tests in a lifetime. A repeat test at age 26 contributes nothing to the mortality benefit.

Nevertheless, additional modifications of the natural history specifications to accommodate high-risk younger women would require a more frequent schedule of examinations under the age of 35 , though at a substantial 'cost' in terms of the total number of examinations required in a population.

\begin{abstract}
A number of recent studies have shown a decreasing trend in both the incidence of, and the mortality from, cervical cancer after the introduction of screening programmes. Miller et $a l^{1}$ showed a significant relationship between the intensity of screening and the reduction in mortality from cancer of the uterus in Canada in women aged 30-64 during the period 1960-62 to 1970-72. In the United States of America Gardner and Lyon ${ }^{2}$ showed that the incidence and mortality from invasive cervical cancer decreased by $59 \%$ and $50 \%$ respectively from 1947 to 1970, while the incidence of carcinoma-in-situ of the cervix increased over the same period. They found a correlation of -0.97 between mortality rates and the rate of cytological screening during those 24 years but they pointed out that the relationship was not necessarily causal considering the widespread decline in mortality before screening was introduced and the increasing number of women removed from risk by hysterectomy. In Iceland ${ }^{3}$ mortality rates from cervical cancer were not falling before the introduction of a screening programme; the mortality
\end{abstract}

rate declined a few years after the programme commenced, and since 1970 a more than twofold reduction has been observed. Hakama ${ }^{4}$ has demonstrated a $50 \%$ decrease in the incidence of cervical cancer in Finland from the 1960s to 1974 . The changes in the mortality rate correlate well with the intensity of screening. ${ }^{5}$ The mortality in 1976 was only one-third of the level 20 years earlier although a decline had been noticed before the introduction of the screening programme.

Recently Miller et $a l^{\mathbf{6}}$ have updated and extended their earlier analysis, including mortality data to 1976 and taking account of the prevalence of women with hysterectomies in the population. They found a significant increase in the decline of mortality from cancer of the uterus from 1966 to 1976 compared with the previous decade. However, the correlation of intensity of screening with the reduction in mortality up to 1976 at the provincial level had disappeared. They concluded that this effect could be due to one of three factors: a failure of screening programmes to reach women most at risk of death, a 
recent increase in the incidence of and the mortality from cancer of the cervix in younger women because of recent greater exposure to risk factors, or a natural history less tractable to intervention by screening than had previously been assumed.

There is, therefore, still room for doubt about the degree of effectiveness of cytological screening programmes for cervical cancer, although the weight of evidence suggests that they should continue. A recent case-control study by Clarke and Anderson ${ }^{7}$ suggests that invasive cancer of the cervix is reduced approximately threefold by a negative cytology smear within five years. However, their sample size did not permit an accurate estimate of the optimal conditions for screening, and the matching of cases and controls on neighbourhood prevents the utilisation of their data to compute the proportion of clinical invasive cancers of the cervix which may be prevented by screening. The task remains to design an optimised screening programme which specifies the age to start, the number of screening tests to be given, the intervals between the tests, and the age to stop. The only practical and ethical way to do this is by mathematical simulation. The data which follow are the results from such a similation.

\section{Materials and methods}

A copy of a screening simulation program reported on in $1973^{8}$ was kindly provided by Professor E. G. Knox of the University of Birmingham. The model is based on a single cohort of 10000 persons traced from birth to death according to the mortalities expressed in a standard life-table. The basic life-table data for the present calculations were derived from Canadian all-causes mortality data in women for 1976. Up to 23 pathological states can be specified for use in the model in addition to three obligatory states: normal, dead of this disease, and dead of other causes. Transitions are possible between each live state in either direction together with one-way transitions from any live state to either dead state. These specifications can be modified by age when transitions occur from a normal to a pathological state or by duration of the pathological state when transitions occur from the pathological state to another or to death. The user is required to specify the rates of transfer as well as the pathological states he intends to use, having initially provided the basic life-table appropriate to the population with which he is working. By adopting different iterations over the transfer rates from one state to another it is possible eventually to mimic what appear to be the appropriate natural history end-points for the disease under consideration. These end-points are assessed by relation to reported rates of incidence and of mortality from the disease in the population from which the basic life-table was derived.

Initial inputs in terms of natural history parameters were derived from the calculated incidence of carcinoma-in-situ (or worse) from the British Columbia cohort study. ${ }^{9}$ It was found that these rates, with cessation of input for carcinoma-in-situ from age 55, could be modelled to approximate to the incidence of invasive cancer of the cervix as recorded in British Columbia in the interval 1955-7 and the mortality from cancer of the cervix as recorded in Canada in 1955. These years were chosen because the data were available and because at that time the impact of screening could have had little effect upon the rates. In simulating these outputs, relatively arbitrary assumptions had to be made over transfer from carcinoma-in-situ (or worse) to invasive cancer and from invasive cancer to death. A number of simulation runs were required to mimic the expected incidence and mortality.

Once the natural history has been simulated, the program permits the introduction of screening procedures. These can be specified in terms of the age of application, the different pathological states amenable to screening, the proportion of the population that accepts the screening offered, and the sensitivity of the screening test. The output from screening will usually be in terms of another pathological state such as 'treated carcinoma-in-situ' which can either be regarded as having only the basic life-table mortality applied to it or be given a specified probability of developing the disease and dying from it. In the simulations reported here, it was assumed that treated carcinoma-in-situ was cured, and hence the former approach was adopted. By applying different screening frequencies, different ages at application of screening, and different intensity loadings, an indication of the potential effectiveness of different screening policies can be obtained. The output of the simulation is in terms of cumulative rates of disease per 10000 born and per 1000 alive together with a matrix of total transitions of pathological types and the specification of the number of tests applied. An assessment of the effects of changes in the input parameters can be made by graphing individual outcome states. A formidable data reduction problem persists, however, in the light of the large number of combinations of input parameters of interest which result in a proliferation of outputs. Therefore an attempt was made, using the statistical technique of multivariate stratification, to produce a summary of the interrelationships of the 
input variables of interest to the outcome variable of potential years of life saved (PYLS).

The runs with the model were deliberately performed without any attempt to include precursor states of carcinoma-in-situ such as dysplasia or states between carcinoma-in-situ and clinically invasive cancers. This was not only to ensure simplicity but because little data are available from the British Columbia cohort study on expected rates of dysplasia and their transition probabilities. The rates utilised from the British Columbia cohort study combined carcinoma-in-situ, microinvasive cancer, and occult invasive cancer as one term designated 'carcinoma-in-situ or worse'.

The first runs of the model did not incorporate transitions from carcinomas-in-situ (or worse) back to normal. When such transitions were incorporated, it was found possible to mimic fairly closely the anticipated cumulative incidence of carcinoma-in-situ (or worse) in a number of different ways, dependent upon how rapidly regression was simulated, and upon the natural history which was actually used. Provided that a balance was achieved between input rates of carcinoma-in-situ and regression, there was little impact of regression as modelled on the cumulated outcome parameters, either incidence of invasive cancer or mortality from cancer of the cervix.

Because there is some evidence that incidence of and mortality from cancer of the cervix is increasing in younger women, ${ }^{610}$ simulation of the impact of screening on mortality from cancer of the cervix was based on an assumption of an earlier and possibly more rapidly progressive natural history than that determined from the British Columbia cohort study in which the younger cohort was born in 1929-33. The input parameters for carcinoma-in-situ or worse as derived from that study were approximately tripled, with increase in the regression terms used, with maximum incidence rates for precursor lesions at ages 25-29 rather than 30-34, and with simulated cumulative mortality in the absence of screening approximately one-third greater than that observed in Canada in 1955 (Table 1). The results presented below are mainly based on this modified natural history. However, in addition, some runs used a 'high-risk' natural history involving twice the incidence rate of carcinoma-in-situ or worse, no further incidence after age 40 , and twice the rate of progression to invasive cancer.

In addition to using mortality, deaths at earlier ages were weighted more heavily than death at older ages, using the potential years of life lost (PYLL) approach. ${ }^{11}$ Knox's model gives cumulative mortality at every age from 20-90 years. Weights for each five-year age group were formed by subtracting the age value at the mid-point of the five-year interval from the last value of the age range, namely 90 . Thus, the weight for the 20-24-year age group would be $90-22 \cdot 5=67 \cdot 5$. There are 14 five-year age groups altogether (Table 1). The total person-years of life lost (PYLL) is defined as the sum of the products of the age-specific weight multiplied by the number of deaths in each five-year age group. The potential years of life saved (PYLS) is defined as the PYLL in the absence of screening minus the screened group PYLL. The PYLS per cent is defined as the PYLS divided by the PYLL in the absence of screening multiplied by 100 . The PYLS, PYLL, and PYLS per cent are perfect linear combinations of each other and therefore only the PYLS and the mortality rate will be used as indicators of the benefit of screening. However, in some of the tabulations the ratio of the total number of screening tests given, divided by the PYLS, is also presented as an indication of the 'cost' of screening. It should be noted that the PYLS is highly correlated with both the total number of tests and the ratio ( $\mathrm{r}=0.81$ and 0.78 respectively).

Table 1 Input and output parameters for simulation in absence of screening

\begin{tabular}{|c|c|c|c|c|}
\hline Age groups (years) & $\begin{array}{l}\text { Incidence (per } 10000) \\
\text { of carcinoma-in-situ } \\
\text { or worse }\end{array}$ & $\begin{array}{l}\text { Modelled prevalence of } \\
\text { clinical invasive carcinoma } \\
\text { (per } 10000 \text { alive) }\end{array}$ & $\begin{array}{l}\text { Modelled cumulative nos. } \\
\text { of deaths from cancer of the } \\
\text { cervix (per } 10000 \text { born) }\end{array}$ & $\begin{array}{l}\text { Weights used in } \\
\text { calculating } P Y L L\end{array}$ \\
\hline $20-24$ & $12 \cdot 5$ & 0.0 & 0.0 & 67.5 \\
\hline $25-29$ & $30 \cdot 0$ & $3 \cdot 0$ & 0.7 & $62 \cdot 5$ \\
\hline $30-34$ & $25 \cdot 0$ & $10 \cdot 0$ & $4 \cdot 0$ & $57 \cdot 5$ \\
\hline $35-39$ & $15 \cdot 0$ & $18 \cdot 0$ & $11 \cdot 6$ & $52 \cdot 5$ \\
\hline $40-44$ & $15 \cdot 0$ & $25 \cdot 0$ & 23.4 & $47 \cdot 5$ \\
\hline $45-49$ & $10 \cdot 0$ & $31 \cdot 0$ & $38 \cdot 6$ & $42 \cdot 5$ \\
\hline $50-54$ & $5 \cdot 0$ & $33 \cdot 0$ & $55 \cdot 6$ & $37 \cdot 5$ \\
\hline $55-59$ & $0 \cdot 0$ & $32 \cdot 0$ & $72 \cdot 3$ & $32 \cdot 5$ \\
\hline $60-64$ & 0.0 & $27 \cdot 0$ & $86 \cdot 4$ & $27 \cdot 5$ \\
\hline $65-69$ & 0.0 & $20 \cdot 0$ & 96.6 & $22 \cdot 5$ \\
\hline $70-74$ & $0 \cdot 0$ & $14 \cdot 0$ & $103 \cdot 0$ & $17 \cdot 5$ \\
\hline $75-79$ & $0 \cdot 0$ & $10 \cdot 0$ & $106 \cdot 5$ & $12 \cdot 5$ \\
\hline $80-84$ & 0.0 & $5 \cdot 0$ & $107 \cdot 9$ & $7 \cdot 5$ \\
\hline $85-89$ & 0.0 & $3 \cdot 0$ & $108 \cdot 3$ & $2 \cdot 5$ \\
\hline
\end{tabular}


Results

BENEFIT VERSUS THE NUMBER OF SCREENING TESTS

Fig. 1 presents the relationship between the total number of tests given in the population, the PYLS, and the mortality rate. The relationship between the mortality rate and the total number of tests up to 14 is nearly perfectly linear. The relationship between the

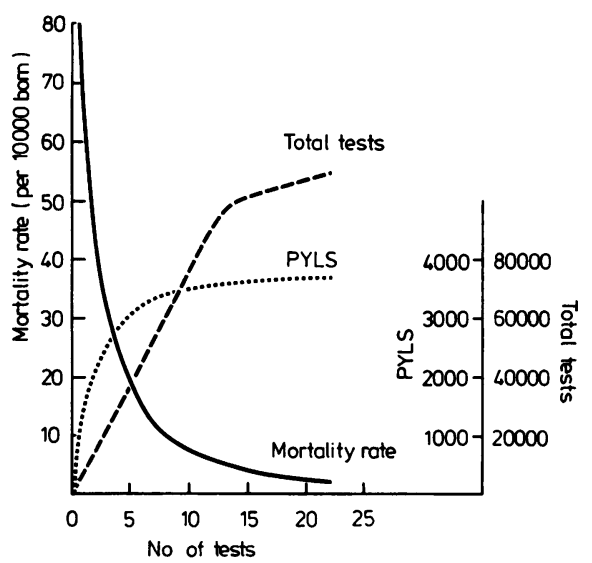

Fig. 1 The relationship of mortality rate, total tests performed, and PYLS to the number of tests performed in a lifetime.

total number of tests and the number of tests per woman can be expressed as follows:

$$
\mathrm{y}_{1}(\text { total tests })=7912 \cdot 3939 \mathrm{x}-474 \cdot 6667
$$

where $\mathbf{x}=$ number of tests per individual.

The PYLS and mortality rate curves are exponential in form and may be expressed mathematically as:

$$
\begin{gathered}
y_{2}(\text { PYLS })=3600-e^{8.0902-0.3671 x} \\
y_{3} \text { (mortality) }=e^{4 \cdot 2698-0.2479 x}
\end{gathered}
$$

where $\mathrm{x}=$ number of tests per individual.

The curves in Fig. 1 show that an increase in the number of screening tests in an individual's lifetime will result in a decreasing return on PYLS and mortality rate due to the asymptotic nature of both curves, and that it will be impossible to abolish mortality from the disease even with a very large number of tests in a lifetime.

If a woman is screened only once in her lifetime, the results of that single screen in terms of PYLS and mortality are shown in Table 2 . If a single screening test is the only possibility, its optimum effect on mortality and on the ratio is obtained if the test is taken at the age of 40 . The optimum effect on PYLS is obtained if the test is taken at the age of 35 .

Table 3 shows the effect of different numbers of screening tests in a woman's lifetime. The end-point used to select the optimal schedule is mortality. A total of 7809 smears will be taken if every 10000 women born receives one test in her life at the age of 40. For every added test per individual, the average increase in the total number of tests given will be about 7670. However, although on average these additional tests result in a further 196 PYLS and a reduction in the mortality rate of $5 \cdot 5 / 10000$, the Table and Fig. 1 indicate that the marginal return for each additional investment in tests becomes less and less. This is most clearly expressed in the increasing ratio of number of tests per PYLS, rising from under 6 with one test to nearly 22 with 10 tests in a lifetime.

Fig. 2 shows the effect on PYLS and mortality from screening two, four, six, eight, and 10 or more times in an individual's lifetime using various schedules. If two tests only are available, a starting age of 35 and an ending age of 40 or 45 produces the maximum PYLS and the minimum mortality outcome under the model. If four screening tests per individual are available, the optimal PYLS-mortality outcome is produced by a starting age of 30 with five-year

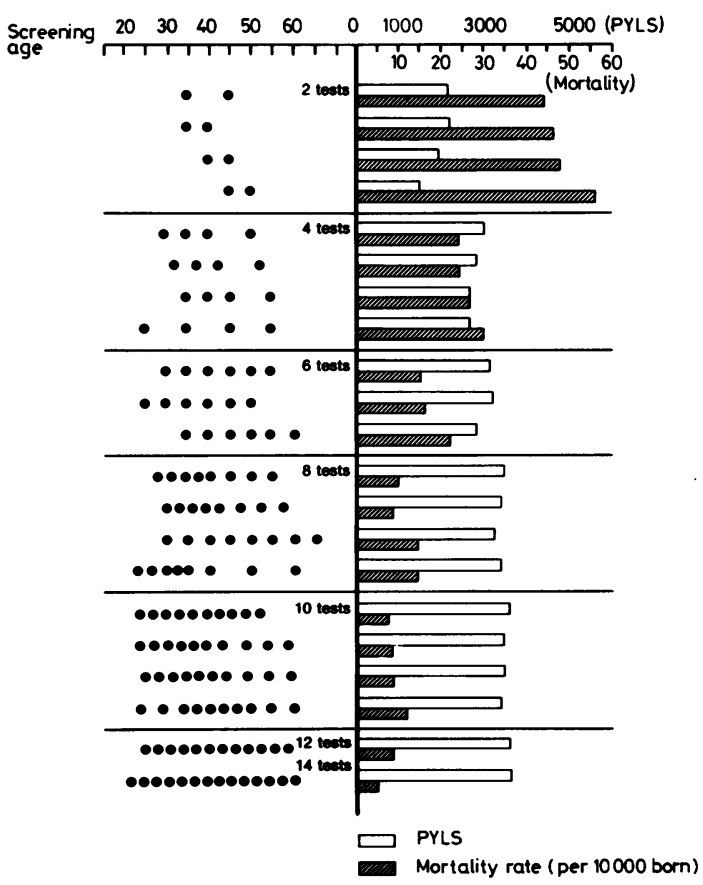

Fig. 2 The relationship of differing numbers of tests at different ages to PYLS and mortality. 
Table 2 Results of a single screening test at different ages

\begin{tabular}{|c|c|c|c|c|c|}
\hline Outcome measure & $\begin{array}{l}\text { Age at test (years) } \\
30\end{array}$ & 35 & 40 & 42 & 45 \\
\hline Mortality per 10000 born & $77 \cdot 4$ & $67 \cdot 6$ & $66 \cdot 8$ & $67 \cdot 5$ & $69 \cdot 5$ \\
\hline \% mortality reduced & $28 \cdot 5$ & $37 \cdot 6$ & $38 \cdot 3$ & $37 \cdot 7$ & $35 \cdot 8$ \\
\hline PYLS & 1226 & 1484 & 1381 & 1300 & 1144 \\
\hline \% PYLL saved* & $32 \cdot 2$ & $39 \cdot 0$ & $36 \cdot 3$ & $34 \cdot 2$ & $30 \cdot 1$ \\
\hline Ratio: total tests to PYLS & $7 \cdot 59$ & $5 \cdot 90$ & $5 \cdot 66$ & $5 \cdot 74$ & $6 \cdot 11$ \\
\hline
\end{tabular}

"Expressed as a percentage of the mortality and PYLL respectively in the absence of screening (3804).

Table 3 Relationship between the numbers of screening tests, PYLS, and mortality per 10000 born, optimised for mortality

\begin{tabular}{|c|c|c|c|c|}
\hline No. of tests per lifetime & $\begin{array}{l}\text { Total no. of tests } \\
\text { per } 10000 \text { born }\end{array}$ & PYLS* & $\begin{array}{l}\text { Ratio no. of tests } \\
\text { per PYLS }\end{array}$ & Mortality \\
\hline 1 & 7809 & 1381 & $5 \cdot 66$ & 66.8 \\
\hline 2 & 15701 & 2150 & $7 \cdot 30$ & $44 \cdot 4$ \\
\hline 3 & 23414 & 2532 & $9 \cdot 25$ & 33.4 \\
\hline 4 & 32028 & 2911 & $11 \cdot 00$ & $24 \cdot 2$ \\
\hline 5 & 38916 & 3081 & $12 \cdot 63$ & $18 \cdot 4$ \\
\hline 6 & 44643 & 3146 & $14 \cdot 19$ & $15 \cdot 1$ \\
\hline 7 & 54123 & 3316 & $16 \cdot 32$ & 11.8 \\
\hline 8 & 62351 & 3412 & $18 \cdot 27$ & 9.4 \\
\hline 9 & 72007 & 3487 & 20.65 & $8 \cdot 1$ \\
\hline 10 & 79443 & 3531 & $22 \cdot 50$ & $7 \cdot 0$ \\
\hline
\end{tabular}

*PYLL in the absence of screening is 3804.

intervals to age 40 and a further test at age 50. Six screening tests per individual are best used starting at age 30 with five-year intervals to age 55. Maximum PYLS and minimum mortality with eight screening tests is gained by starting at age 28 with four more screening tests at three-year intervals followed by three tests at five-year intervals, ending at age 55. If 10 screening tests per individual are available, the optimum starting age is 25 with 10 screens at three-year intervals to age 52. A schedule of triennial screens from age 25 to age 45 followed by three screens at five-year intervals ending at age 60 is almost as good.

Thus, as more tests per individual lifetime become available, the optimal age to begin screening decreases from 40 to 25 , and the optimum interval between the initial screenings decreases from 10 years in the case of two tests to three years. However, it is acceptable to lengthen the interscreening period to five years after the age of 40 .

\section{THE FACTORS WHICH AFFECT PYLS}

\section{(1) The effect of missed screening tests}

It is not unusual for a woman to miss one or more screening tests over a period of several years. The effect was simulated of missing one or two tests if the total planned for a lifetime was six or 11. It was found that PYLS is reduced by a greater extent (and the mortality rate increased to a corresponding extent) if a screening test is lost from a programme with fewer individual screens than with more. Further, in a programme of six tests per lifetime the impact is greater if the missed screening occurs at an earlier age, especially before age 45 . This is due, of course, to a natural history specification which assumes that disease occurs relatively early in life as well as to the higher mortality weights accorded to women in younger age groups. With 11 planned tests, however, there is more impact on the outcome parameters if tests are missed at middle rather than older or younger ages.

\section{(2) The effect of the interval between screening}

Table 4 shows that for eight tests per lifetime the most effective spacing of screening is to begin with three-year intervals which change to five-year intervals after the age of 35 . For 10 tests per lifetime, there is little to choose between a three-yearly schedule from age 25 to 52 and three-yearly from 25 to 40 and five-yearly to age 60 . However, 11 tests per lifetime should be given three-yearly from ages 25 to 55.

\section{(3) The effect of acceptance of screening}

Not all women invited for screening will attend and this must be taken into account when judging the effectiveness of the screening programme as a whole. Table 5 shows the effect of three different levels of acceptance of screening (expressed as \% acceptance) on a programme of 10 lifetime screens per individual. An $80 \%$ acceptance level can save about $50 \%$ more PYLS and reduce the mortality about $64 \%$ more than a $50 \%$ acceptance rate. An acceptance of $90 \%$ will save about 70\% more PYLS and reduce the mortality about $75 \%$ more than a $50 \%$ acceptance. The bottom 
Table 4 The effect of intervals between screens on mortality and PYLS

\begin{tabular}{|c|c|c|c|c|}
\hline Interval (years) & Screening test applied at ages: & No. of tests per lifetime & Mortality per 10000 born & PYLS \\
\hline All 3 & $\begin{array}{llllllll}28 & 31 & 34 & 37 & 40 & 43 & 46 & 49\end{array}$ & 8 & $10 \cdot 8$ & 3404 \\
\hline 3,5 & $262932 \quad 35^{*} 40 \quad 45 \quad 5055$ & 8 & $9 \cdot 6$ & 3422 \\
\hline $5,3,5$ & $253035^{*} 38 \quad 41 \quad 44^{*} 4954$ & 8 & $10 \cdot 0$ & 3387 \\
\hline 5,3 & $\begin{array}{llllllll}25 & 30 & 35 & 40^{*} & 43 & 46 & 49 & 52\end{array}$ & 8 & $10 \cdot 8$ & 3352 \\
\hline All 5 & $\begin{array}{llllllll}23 & 28 & 33 & 38 & 43 & 48 & 53 & 58\end{array}$ & 8 & $11 \cdot 4$ & 3313 \\
\hline All 3 & $\begin{array}{llllllllll}25 & 28 & 31 & 34 & 37 & 40 & 43 & 46 & 49 & 52\end{array}$ & 10 & $7 \cdot 0$ & 3531 \\
\hline 3,5 & $\begin{array}{llllllllll}25 & 28 & 31 & 34 & 37 & 40^{*} & 45 & 50 & 55 & 60\end{array}$ & 10 & $7 \cdot 1$ & 3504 \\
\hline $5,3,5$ & $\begin{array}{llllllllll}25 & 30 & 35^{*} & 38 & 41 & 44 & 47 & 50^{*} & 55 & 60\end{array}$ & 10 & $8 \cdot 0$ & 3432 \\
\hline 5,3 & $\begin{array}{llllllllll}25 & 30 & 35^{*} & 38 & 41 & 44 & 47 & 50 & 53 & 56\end{array}$ & 10 & $7 \cdot 9$ & 3438 \\
\hline All 5 & $\begin{array}{llllllllll}25 & 30 & 35 & 40 & 45 & 50 & 55 & 60 & 65 & 70\end{array}$ & 10 & $11 \cdot 1$ & 3335 \\
\hline All 3 & $\begin{array}{lllllllllll}25 & 28 & 31 & 34 & 37 & 40 & 43 & 46 & 49 & 52 & 55\end{array}$ & 11 & $5 \cdot 6$ & 3558 \\
\hline 3,5 & $\begin{array}{lllllllllll}22 & 25 & 28 & 31 & 34 & 37 & 40^{*} & 45 & 50 & 55 & 60\end{array}$ & 11 & $6 \cdot 7$ & 3528 \\
\hline 5, 3. 5 & $20 \quad 2530^{*} 33 \quad 36 \quad 39 \quad 42 * 47 \quad 52 \quad 57 \quad 62$ & 11 & $8 \cdot 0$ & 3463 \\
\hline 5,3 & 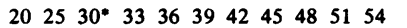 & 11 & 6.8 & 3508 \\
\hline All 5 & $\begin{array}{lllllllllll}20 & 25 & 30 & 35 & 40 & 45 & 50 & 55 & 60 & 65 & 70\end{array}$ & 11 & $10 \cdot 9$ & 3322 \\
\hline
\end{tabular}

- Screening interval changes after this test.

Table 5 Effect of the acceptance level of screening on mortality and PYLS

\begin{tabular}{|c|c|c|c|c|}
\hline Screening test applied at ages: & No. of tests per lifetime & Acceptance level (\%) & Mortality per 10000 born & PYLS \\
\hline $\begin{array}{llllllllll}25 & 28 & 31 & 34 & 37 & 40 & 45 & 50 & 55 & 60 \\
25 & 28 & 31 & 34 & 37 & 40 & 45 & 50 & 55 & 60 \\
25 & 28 & 31 & 34 & 37 & 40 & 45 & 50 & 55 & 60 \\
20 \text {, annual to } 30, \text { two-yearly to } & 42, \\
\text { three-yearly to } & 60\end{array}$ & $\begin{array}{l}10 \\
10 \\
10\end{array}$ & $\begin{array}{l}50 \\
80 \\
90\end{array}$ & $\begin{array}{r}19.5 \\
7.1 \\
5.0\end{array}$ & $\begin{array}{l}3042 \\
3504 \\
3585\end{array}$ \\
\hline
\end{tabular}

row of the table indicates the effect of a substantial increase in test frequency (a modified 'annual' schedule) in an attempt to compensate for a $50 \%$ acceptance level. Even with 23 tests, full compensation is not achieved. Thus, a greater return in reduction in mortality and increase in PYLS is obtained by an increase in the proportion of the population accepting screening than by an increase in the planned numbers of tests per lifetime at the same acceptance level. All other simulations in this paper are, in fact, based on an $80 \%$ acceptance rate.

\section{(4) The effect of sensitivity of the test}

Although all other analyses presented are based on a test sensitivity of $75 \%$, a realistic level in the light of the findings from the British Columbia cohort study, ${ }^{12}$ such a level may not be achieved in all circumstances. In Table 6, the effect on mortality and PYLS is examined for a schedule involving 10 tests per lifetime. It is apparent that reducing the test sensitivity to $55 \%$ nearly doubles the mortality while reducing the PYLS. The lower line indicates that a substantial increase in number of tests is required in order to compensate for a low sensitivity.

\section{MULTIVARIATE STRATIFICATION}

The results presented so far have been selected from 137 different simulations, many of which were summarised in graphical and tabular form. It is very difficult, however, to summarise the simultaneous effects of the various independent variables on the single dependent variable (PYLS). A suitable analytic approach for this summary is a stratification technique ${ }^{13}$ which has proved useful in delineating subgroups of patients in clinical trials prognostic analyse ${ }^{14}$ and in other settings where it is necessary to summarise the joint effect of a large number of independent variables. The analysis operates by successively dividing the original data set into pairs of subgroups which differ as much as possible from each other with respect to their mean values on the dependent variable. Each of the subgroups may then be eligible to be further subdivided at the class interval of the independent variable which accounts

Table 6 Effect of sensitivity of the test on mortality and PYLS

\begin{tabular}{|c|c|c|c|c|}
\hline Screening test applied at ages: & No. of tests per lifetime & Sensitivity of test (\%) & Mortality per 10000 born & PYLS \\
\hline $\begin{array}{llllllllll}25 & 28 & 31 & 34 & 37 & 40 & 45 & 50 & 55 & 60 \\
25 & 28 & 31 & 34 & 37 & 40 & 45 & 50 & 55 & 60 \\
25 & 28 & 31 & 34 & 37 & 40 & 45 & 50 & 55 & 60 \\
20, & \text { annual to } 30 \text {, two-yearly to } 42, \\
\text { three-yearly to } 60 & \end{array}$ & $\begin{array}{l}10 \\
10 \\
10\end{array}$ & $\begin{array}{l}55 \\
75 \\
95\end{array}$ & $\begin{array}{r}14.6 \\
7 \cdot 1 \\
3.4\end{array}$ & $\begin{array}{l}3224 \\
3504 \\
3651\end{array}$ \\
\hline
\end{tabular}




\section{Cervical screening in Canada}

for the largest amount of dependent variable variation in the subgroup. The results of this analysis are presented as a hierarchical 'tree' diagram in Fig. 3.

The whole data set is initially split on the total number of screening tests per individual. This creates three subgroups (numbers 2, 3 and 4). Thus, an optimal screening programme should deliver at least nine screening tests per woman in her lifetime. Three subgroups are distinguished within Group 4 on the basis of the interval in years between screening tests. Progressively shorter intervals are associated with increasing mean PYLS values, even between four and five years. The short-interval subgroup (\#7) is split on age at first screening. It is clear that when nine or more tests are given at two-to-three-year intervals, the potential saving in PYLS is reduced if the start of screening is delayed past the age of 25 .

The 61 different low-mean PYLS screening strategies diverted to Group 2 and Group 3 contain considerable variation in PYLS as the further splits reveal. The partition on Group 3 shows that if six to eight tests are available it is important that they begin before the age of 33 to achieve maximum benefit. (In fact, six to eight tests begun before that age results in a higher mean PYLS than nine or more tests given at five-year intervals). The split on Group 2 shows that a 0 year interval between tests (by definition, one screening per lifetime) results in by far the lowest saving of PYLS.

The analysis also considered the effect of the variables end age (for screening) and whole interval (elapsed time between first and last screening test) but neither were selected for a split because at least one of the other three input variables were successful in accounting for more variation in PYLS at every step.

The stratification model represented by the 'tree' (Fig. 3) accounts for $85 \%$ of the variation in PYLS in the overall data set. This amount of explaining power is felt to provide an adequate summary of the multitude of combinations of inputs in the 137 runs.

RECOMMENDATIONS OF THE CANADIAN TASK FORCE REPORT

In the 1976 Canadian Task Force Report ${ }^{15}$ the main recommendation was that women at risk receive

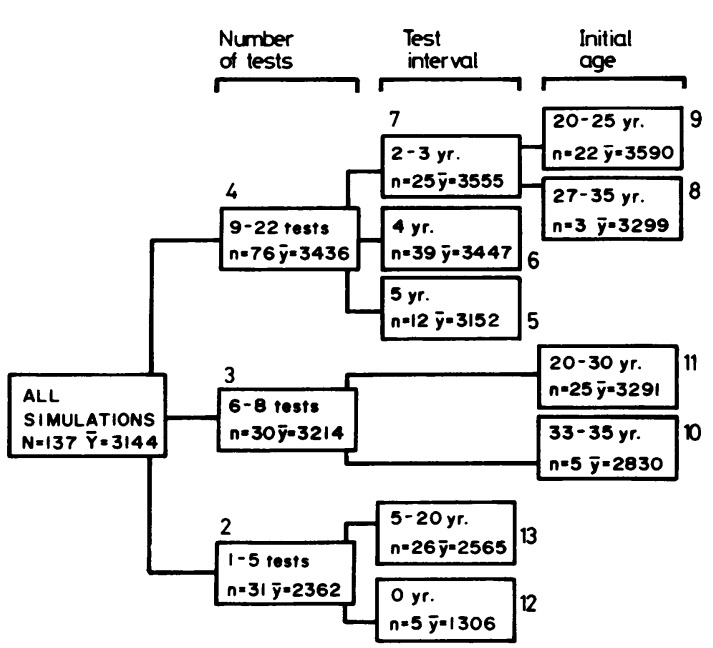

Fig. 3 Number of screening simulations $(n)$ and mean PYLS $(y)$ resulting from a multivariate stratification analysis.

'Pap' smears one year apart for the first two years and then at intervals of every three years (if the earlier tests were negative) until the age of 35 . Smears were to be given subsequently at five-year intervals until the age of 60 , when screening would stop in cytologically normal women. The mortality and PYLS which result from five combinations of recommendations of the Task Force Report in the general population are shown in Table 7. Comparing rows 2 and 3 and rows 4 and 5 shows that taking the second smear a year after the first neither increases the PYLS nor decreases the mortality. In addition, the choice of age 20 as an initial age for screening is better than either 19 or 16 . It is instructive to compare rows 2 and 3 in Table 7 which show a mortality rate of 8.7 based on either 11 or 12 screening tests with rows 9 and 10 in Table 3 which show that a comparable mortality rate and PYLS can be achieved based on nine or ten screening tests. These results indicate that the recommendations of the Task Force Report can be improved upon in terms of costs while preserving an equal degree of benefit.

Table 7 The effect of variation of the recommendations of the Canadian Task Force (1976) report on mortality and PYLS

\begin{tabular}{|c|c|c|c|}
\hline Screening test applied at ages: & No. of tests per lifetime & Mortality per 10000 born & PYLS \\
\hline $\begin{array}{llllllllllll}16 & 19 & 22 & 25 & 28 & 33^{*} & 38 & 43 & 48 & 53 & 58 & \\
18 & 19 & 22 & 25 & 28 & 31 & 3^{*} & 40 & 45 & 50 & 55 & 60 \\
& 19 & 22 & 25 & 28 & 31 & 3^{*} & 40 & 45 & 50 & 55 & 60 \\
19 & 20 & 23 & 26 & 29 & 32 & 35^{*} & 40 & 45 & 50 & 55 & 60 \\
& 20 & 23 & 26 & 29 & 32 & 35^{*} & 40 & 45 & 50 & 55 & 60\end{array}$ & $\begin{array}{l}11 \\
12 \\
11 \\
12 \\
11\end{array}$ & $\begin{array}{r}10 \cdot 3 \\
8 \cdot 7 \\
8 \cdot 7 \\
7 \cdot 8 \\
7 \cdot 8\end{array}$ & $\begin{array}{l}3372 \\
3446 \\
3446 \\
3484 \\
3484\end{array}$ \\
\hline
\end{tabular}

*Screening interval changes follows this test. 
Table 8 Results of screening 'high-risk' women*

\begin{tabular}{|c|c|c|c|c|c|c|}
\hline \multicolumn{5}{|c|}{ SCREENING SCHEDULE } & \multirow[b]{2}{*}{$\begin{array}{l}\text { Mortality } \\
\text { per } 10000 \text { born }\end{array}$} & \multirow[b]{2}{*}{$P Y L S$} \\
\hline Starting age & Frequency & Age before change & Age at end & $\begin{array}{l}\text { No. of tests } \\
\text { per lifetime }\end{array}$ & & \\
\hline 25 & 3,5 yearly & 40 & 60 & 10 & $28 \cdot 6$ & 4549 \\
\hline 25 & 3 yearly & & 58 & 12 & $11 \cdot 0$ & 5383 \\
\hline 25 & 1,5 yearly & 35 & 60 & 16 & $3 \cdot 1$ & 5798 \\
\hline 22 & 3,5 yearly & 40 & 65 & 12 & $9 \cdot 8$ & 5461 \\
\hline 20 & 3,5 yearly & 35 & 60 & 11 & $11 \cdot 0$ & 5413 \\
\hline 20 & 1,5 yearly & 35 & 60 & 21 & $1 \cdot 3$ & 5906 \\
\hline 20 & 1,3 yearly & 35 & 59 & 24 & $1 \cdot 1$ & 5916 \\
\hline
\end{tabular}

*In the absence of screening the mortality per 10000 born is 132.7 and the PYLL is 5973.

THE PROBLEM OF THE HIGH-RISK SUBGROUP In the 1976 Task Force Report ${ }^{15}$ a subgroup of at-risk women were defined as high-risk if they had multiple sexual partners and an early onset of first intercourse. Women at high risk were recommended for annual screening, at least while they remained at high risk. In Table 8 a summary is presented of the simulation runs involving the 'high-risk' natural history. It appears that, for maximum impact, screening should start at age 20 in this subgroup. Further, at the level of 12 tests per lifetime, a three-yearly schedule stopping at age 53 results in $92 \%$ of the maximal PYLS. However, the 11-test schedule modelled on the Task Force recommendations is almost as good, resulting in over $90 \%$ of the maximal PYLS.

An annual frequency from age 20 to 35 and fiveyearly thereafter requires 21 tests in a lifetime but achieves almost $99 \%$ of the theoretical maximum of PYLS at a 'cost' of a ratio of 30.4 tests per PYLS. Delaying the onset of screening to age 25 reduces the benefit to $97 \%$ of the maximal PYLS but also reduces the 'cost' to 22.6 tests per PYLS. Maximal benefit in these simulations with this natural history was achieved with annual screening from age 20 to 35 and three-yearly to age 60 , with $99 \%$ of the maximal PYLS but at a 'cost' of 34 tests per PYLS.

\section{Discussion}

On a worldwide basis cervical cancer is probably the most common form of cancer in women. In Canada and the USA it is still an important cause of death. In low socioeconomic groups cervical cancer may be more common than breast cancer. Cytology screening provides a valid, accurate, reliable, and inexpensive method of detecting the disease at the precancerous stage. ${ }^{12}$ Many countries have instituted cervical cytology screening programmes for the secondary prevention of cancer of the cervix. In Britain there appears to have been more awareness of the cost of screening versus hysterectomy ${ }^{814}$ and programmes have been advocated which do not begin screening until age 35 in asymptomatic women. ${ }^{16} \mathrm{Knox},{ }^{17}$ using a simplified version of the model used in the present analysis, concluded that a series of 10 screening tests for women between the ages of 35 and 80 would be optimal, and capable of preventing about $77 \%$ of all deaths from cervical cancer. Spriggs and Husain ${ }^{18}$ suggested that a screening programme should start at age 25 with screens at five-year intervals until age 35 , at which time the interval would shorten to every three years until age 70. Only those women who were not screened until age 35 were recommended for a repeat test after one year. MacGregor, ${ }^{19}$ on the basis of her experience in Aberdeen, Scotland, advocated commencement of screening no earlier than the age of 25 .

In the USA the annual screening programme has been in effect for a long time, but has been criticised by Foltz and Kelsy. ${ }^{20}$ Other observers, using various simulation approaches, also suggest that the cost of annual screening of cervical cancer is too high in comparison to the number of lives saved. ${ }^{21}{ }^{22}$ The American Cancer Society has recently changed its policy of one screen a year to a recommendation for 'regular' screening. The decision as to what is 'regular' is left to a woman and her physician but should involve a screen at least every three years, from ages 20 to $65 .{ }^{23}$ 'Pap' tests are also recommended by the society for women under 20 who are sexually active and women with other highrisk characteristics. The NIH Consensus Development Conference on Cervical Cancer Screening, however, was recently unable to decide between annual versus three-yearly screening. ${ }^{24}$ In Finland $^{5}$ a large proportion of all women are screened for cervical cancer every five years starting at age 25 and ending at age 55 . In Iceland ${ }^{3}$ women are eligible to enter screening programmes at the age of 25 and have commonly had their last screening tests at age 60 although the upper age limit has now been prolonged to 70 with a screening interval of two or three years. 
Since population characteristics differ from country to country, screening programmes advocated as optimal in other areas will not necessarily be suited to the Canadian population. However, the results of applying the screening strategies from these various countries to the Canadian life-table experience in the screening model (using the modified but not the highrisk natural history) indicated that:

1. Screening which begins at the age of 35 is too late to have an optimal effect.

2. Postponing the end age for screening does not usefully increase the benefit.

3. Repeating the first two screening tests at an interval of one year in cytologically normal women neither increases the PYLS nor decreases the mortality rate.

However, if a programme can afford 12 tests a lifetime, a three-yearly schedule with screening ending at age 58 is preferable. If cost is no consideration, and 20 tests a lifetime is considered feasible, annual screening from age 25 to age 31 and biennial thereafter to age 61 produces a substantial benefit. For the high-risk subgroup, near maximal benefit is obtained if screening commences at age 20 , is annual to age 35 , but thereafter can revert to a three-year or even a five-year schedule.

Miller et $^{a} l^{6}$ have shown that Canadian mortality trends from a period when annual screening was presumed to be in effect was probably not succeeding in abolishing mortality from cancer of the cervix. The results when different acceptance rates were simulated in the present analysis suggest a possible explanation for this finding. Indeed, it should be noted that the variation in acceptance rates in the simulations are applied randomly over the whole population. However, in practice, variations in the level of acceptance of cervical screening do not operate at random. Studies of this issue have shown that the same people tend to refuse opportunities for screening, and that these tend to be women at high risk of the disease. Thus, in one Manchester regional survey only $72 \%$ of women undergoing screening returned for a repeat screening three years later..$^{25}$ In the Federal Republic of Germany it was found that as the number of individual risk factors for cervical cancer increased, the probability that a woman would attend screening often or regularly rapidly decreased. ${ }^{26}$ Hence the adverse effects will be even greater than those modelled in the simulations presented. This implies that further concentration on rescreening frequency in women who largely accept the programme will not be rewarding, and that a higher cost-effectiveness will be achieved by persuading all women to enter the programme and accept screening at a reasonable frequency.

There is still widespread disagreement on an ideal screening frequency and the annual examination still has many proponents. When the Canadian Task Force Report ${ }^{15}$ was published, the Society of Obstetricians and Gynecologists of Canada maintained that annual cytological screening of the cervix was a reasonable safeguard against cancer and should continue. ${ }^{27}$ This view is also held in the USA. ${ }^{28}$ Some proponents of annual screening base their view on the presence of laboratories with poor quality control programmes that produce results of low sensitivity. Our results tend to confirm that increased frequency can compensate for low sensitivity. Nevertheless it would seem more sensible to counteract that primary deficiency in laboratories, rather than unnecessarily expending resources on repetitive rescreening.

Richart and Barron ${ }^{29}$ calculated that there was a $60 \%$ probability for lesions classified as dysplasia to progress to carcinoma-in-situ after 10 years. Sachs ${ }^{30}$ summarised the experience of 10425 cases of carcinoma-in-situ from eight countries ${ }^{31}$ and found that $9-16 \%$ of all cases had been observed in women under 30. Although there is still room for doubt as to the proportion of cases of dysplasia that will progress, these findings provide further indirect evidence that an ideal screening programme in women of normal risk would begin at about age 25 . Although dysplasia was not directly simulated in the present analyses, those cases that progress can be regarded as being modelled within the designation 'carcinoma-in-situ or worse' in Table 1.

The findings of the present analysis, therefore, show that a screening programme in normal-risk women which comprises about nine screening tests with an $80 \%$ acceptance can result in $92 \%$ of the maximal person-years of life that could be saved and reduce mortality from cancer of the cervix by about $93 \%$. In high-risk women more intensive programmes starting at a younger age are required to achieve the same impact. Nevertheless, these results are dependent on the type of natural history we modelled being a close approximation to the truth. Even if an $80 \%$ population acceptance was achieved, a proportion of cases of the detectable preclinical phase of the disease might have a progression so rapid that they could not be detected in any reasonably feasible programme. To the extent that such cases occur, clinical invasive cases of cancer of the cervix and mortality from the disease is inevitable. Only further observation of programmes with near-maximum acceptance levels will settle this issue.

It is important to recognise that if the natural history modelled in this paper is a reasonable approximation of that currently operative in younger women in Canada, it may not apply to older women 
who have not yet entered a screening programme or who have had minimal screening by now. If the onset of preclinical disease were to be delayed by 10 years, the recommended ages to start and finish screening would be similarly delayed. Thus, if a woman otherwise at risk is found in her forties, fifties, or sixties never to have participated in a programme, she should undoubtedly be offered screening, and a repeat smear would be desirable one year later to offset the effect of an initial false-negative examination. However, if two or three smears at appropriate intervals were negative, she could be regarded as of low risk, and it would probably be satisfactory to cease screening once she reached the age of 65 or 70 .

Reprints from Dr. A. B. Miller, NCIC Epidemiology Unit, Faculty of Medicine, University of Toronto, McMurrich Building, Toronto, Ontario M5S 1A8.

\section{References}

${ }^{1}$ Miller AB, Lindsay J, Hill GB. Mortality from cancer of the uterus in Canada and its relationship to screening for cancer of the cervix. Int J Cancer 1976; 17: 602-12.

${ }^{2}$ Gardner JW, Lyon JL. Efficacy of cervical cytologic screening in the control of cervical cancer. Prev Med 1977; 6: 487-99.

${ }^{3}$ Johannesson G, Geirrson G, Day N. The effect of mass screening in Iceland, 1965-1975, on the incidence and mortality of cervical carcinoma. Int J Cancer 1978; 21: 418-25.

${ }^{4}$ Hakama M. Mass screening for cervical cancer in Finland. In: Miller AB, ed. Screening in cancer. Geneva: International Union Against Cancer, 1978: 93-107.

${ }^{5}$ Hakama M, Rusanen-Virtanen U. Effect of a mass screening program on the risk of cervical cancer. Am J Epidemiol 1976; 103: 512-7.

- Miller AB, Visentin T, Howe GR. The effect of hysterectomies and screening on mortality from cancer of the uterus in Canada. Int J Cancer 1981; 27: 651-7.

'Clarke EA, Anderson TW. Does screening by 'Pap' smears help prevent cervical cancer-a case-control study. Lancet 1979 ; ii: $1-4$.

- Knox EG. A simulation system for screening procedures. In: The future and present indicatives, ninth series. Oxford: Nuffield Provincial Hospital Trust, Oxford University Press, 1973: 93-107.

- Boyes DA, Morrison B, Knox EG, Draper GJ, Miller AB. A cohort study of cervical cancer screening in British Columbia. Clinical and Investigative Medicine 1981; (in press).
${ }^{10}$ Yule R. Mortality from carcinoma of the cervix. Lancet 1978; i: $1030-2$.

${ }^{11}$ Romeder J-M, McWhinnie JR. Potential years of life lost between ages 1 and 70: An indicator of premature mortality for health planning. Int J Epidemiol 1977; 6: 143-51.

${ }^{12}$ Miller AB. An evaluation of population screening for cervical cancer. In: Koss LG, Coleman DV, eds. Advances in clinical cytology. London: Butterworths, 1981: 64-94.

${ }^{13}$ Andersen R, Smedby B, Ekland C. Approaches and techniques-automatic interaction detector program for analyzing health survey data. Health Services Res 1971; Summer: 165-83.

${ }^{14}$ Holland WW. Taking stock. Lancet 1974; i: 1494-7.

${ }^{15}$ Canadian. Task Force appointed by the conference of deputy ministers of health. Cervical cancer screening programs. Can Med Assoc J 1976; 114: 1003-33.

${ }^{16}$ Bindle G, Wakefield J, Yule R. Cervical smears: are the right women being examined? $\mathrm{Br}$ Med J 1976; i: 1196-7.

${ }^{17}$ Knox EG. Age and frequencies for cervical cancer screening. BrJ Cancer 1976; 34: 444-52.

${ }^{18}$ Spriggs AI, Husain OAN. Cervical smears. $\mathrm{Br}$ Med $\mathrm{J}$ 1977; i: $1516-8$.

${ }^{19}$ MacGregor JE, Teper S. Uterine cervical cytology and young women. Lancet 1978; i: 1029-31.

${ }^{20}$ Foltz AM, Kelsey JL. The annual Pap test: a dubious policy success. Milbank Mem Fund $Q$ 1978; 56: 426-62.

${ }^{21}$ Eddy DM. Screening for cancer: Theory, analysis and design. New Jersey: Prentice Hall, 1980.

${ }^{22}$ Galliher HP. Cost-effective planned lifetime schedules of pap smears: estimated maximal potentials. Detroit: The Michigan Cancer Foundation, 1976.

${ }^{23}$ American Cancer Society. ACS report on the cancer-related health check-up CA Cancer Journal for Clinicians 1980; 30: 194-240.

${ }^{24}$ National Institutes of Health. Cervical cancer screening: The Pap smear. National Institutes of Health Consensus Development Conference summary vol. 3, no. 4. Washington DC: US Government Printing Office, 1980.

${ }^{25}$ Sansom LD, MacInerney J, Oliver V, Wakefield J, Yule $R$. Recall of women in a cervical cytology screening programme. Br J Prev Soc Med 1975; 29: 131-4.

${ }^{26}$ Pauli HK. Epidemiology - some new aspects on the prevention of cervical cancer, In: Burghardt E.et al, eds. Cervical pathology and colposcopy Stuttgart: Georg Thieme, 1978: 111-9.

${ }^{27}$ Schmidt OA. Cervical cancer screening programs: The SOGC's view (c). Can Med Assoc J 1977; 116: 971.

${ }^{28}$ Homesley HD. Evaluation of the abnormal Pap smear. Am Fam Physician 1977; 16: 190-4.

${ }^{29}$ Richart RM, Barron BA. A follow-up study of patients with cervical dysplasia. Am J Obstet Gynecol 1969; 105: 386-93.

${ }^{30}$ Sachs $\mathrm{H}$. Epidemiology of carcinoma in situ of cervix uteri. In: Burghardt E et al, eds. Cervical pathology and colposcopy. Stuttgart: Georg Thiem, 1978: 119-23.

${ }^{31}$ Doll R, Muir CS, Waterhouse JAH, eds. Cancer incidence in five continents, vol. 2. Geneva: Springer, 1970. 